\title{
Theoretical and Experimental Studies for a Double Pass Solar Air Heater
}

\author{
Ammar A. Farhan, PhD \\ Mechanical Eng. Dept. \\ University of Baghdad \\ Iraq - Baghdad
}

\begin{abstract}
The performance characteristics of double pass solar air heater (DPSAH) were evaluated theoretically and experimentally. Actual hourly weather data for Baghdad, Iraq was used to assess the DPSAH in December 2016 and January 2017. The results of the study indicated that increasing airflow rate through the collector increases the instantaneous efficiency and the useful energy gained but it reduces the air outlet temperature rapidly. An air outlet temperature was about 37 ${ }^{\circ} \mathrm{C}$ at midday for airflow rate of $0.01 \mathrm{~m}^{3} / \mathrm{s}$. The maximum value of the average performance line was $63 \%$. It was found that the present DPSAH outlet air temperature greater than single pass solar air heater (SPSAH) by $3{ }^{\circ} \mathrm{C}$ for the same airflow rate. Moreover, the average difference between the theoretical and the experimental results was $3 \%$.
\end{abstract}

\section{Keywords}

Double pass, solar air heater, experimental study, mathematical model, performance study.

\section{INTRODUCTION}

Since the last century, when the oil crisis problem was appeared which pushed the researchers to find an alternative sources for energy. Many sources were discovered like solar, wind, biomass, nuclear, etc. But the use of some of them causes the greenhouse effects and global warming potential which threatens the life. So, researchers found themselves in a situation to save lives through discovered an efficient energy sources having the following features: available, cheap, and environmentally friendly. The Sun represents a suitable source that's had this feature. Iraq like many countries in the Middle East have more than 250 clear sunny days around the year and the solar intensity reaches $1000 \mathrm{~W} / \mathrm{m} 2$ at solar noon.

Solar air heater (SAH) represents the simplest way to convert the solar intensity into heat, which can be used in domestic, manufacturing, and agriculture applications. The advantages of SAH are: it can be constructed from available material, cheap and easy building, less pressure drop across it, and no corrosions and freezing of air during the work as compared with solar water heater. On the other hand, the disadvantages were: low efficiency, a low air density, which required more quantity of air mass flow rate, and low thermal capacity of air, so it could not be used as a storage fluid [1].

To enhance the thermal performance of SAH, different techniques were used. Ho et al. [2]were presented a theoretical and experimental work to study the effect of recycle air flow and baffles, fins attached with absorber plate on the thermal efficiency. They found that, the recycle air flow was increasing the collector efficiency. A photovoltaic-thermal (PV/T) DPSAH with fins were investigated by Othman et al. [3] to study the effect of combined double pass and fins on the heat transfer between air flow and the absorber plate. They found that the used of DPSAH with fins enhanced the thermal and electrical efficiencies. Ali et al. [4] carried out an experimental study to find the performance of DPSAH with different thermal storage medium (TSM). They aimed to exploit the latent heat of TSM during sunset to provide the required heat. They showed that SAH with TSM provided heat for 1.5 hours more than SAH without TSM.

The exegetic analysis of DPSAH, double glass cover with Vcorrugated absorber plate were presented by Hedayatizadah et al. [5]. They reported that, the temperature difference between absorber plate and the sun had an important role and its value reaches $63.57 \%$ of the exergy losses. Transverse ribs were used in DPSAH by Dogra et al. [6] to investigate its effect on heat transfer and friction factor experimentally. They found that, the uses of ribs improves heat transfer and thermal performance of SAH. While, the friction factor occurs at relative roughness pitch 10 has the maximum value. The thermal and hydraulic performance of DPSAH with an artificial roughness (ribs) distributed above and below the absorber plate were studied experimentally by [7] and [8]. They concluded that, the contribution of ribs on each side of the absorber plate enhanced the thermal and hydraulic efficiencies.

Gonzalez et al. [9] were studied the counter flow DPSAH with a flat absorber plate experimentally for different air mass flow rate. They reported that, the temperature rise across the DPSAH was $40 \mathrm{oC}$ for $0.02 \mathrm{~kg} / \mathrm{s}$ air mass flow. While, the maximum efficiency was $50 \%$. Farhan [10] presented a comparison study between counter flow DPSAH with single pass (SP) SAH. The two SAHs had a V-corrugated absorber plate. He found that, the maximum value of thermal performance curve for DPSAH and SPSAH were $68 \%$ and 61 $\%$, respectively. Different techniques have been used to enhance the performance of DPSAH were reported by Ravi and Saini [11]. They presented the theoretical and experimental investigations which be considered by researchers to increase the useful energy exploited from DPSAH. Few studies have been reported with corrugated absorber surface [12].

In this study, the single glass parallel flow DPSAH with Vcorrugated absorber plate was investigated and analyzed theoretically and experimentally. The thermal performance and heat transfer coefficient were compared for different air mass flow rates. This research aimed to find out the impact of the double pass on the thermal performance of SAH.

\section{MATHEMATICAL MODEL}

To model the DSAH, a number of simplifying assumptions are made to lay the foundations without obscuring the basic physical situations. These important assumptions are[13]: 
1. The solar air heater is simulated under steady state conditions.

2. Heat flow through the glass cover as well as through the side and back insulation are one dimensional.

3. The cover is opaque to infrared radiation.

4. The sky can be considered as a black body for long wavelength radiation at an equivalent sky temperature.

5. Properties of the collector materials are independent of temperature.

At steady state, Fig. 1 shows the heat transfer coefficients between each component of the DPSAH. Thereby, the thermal resistance network is represented in Fig. 2. So, the energy balance equations for each component are listed as follows:

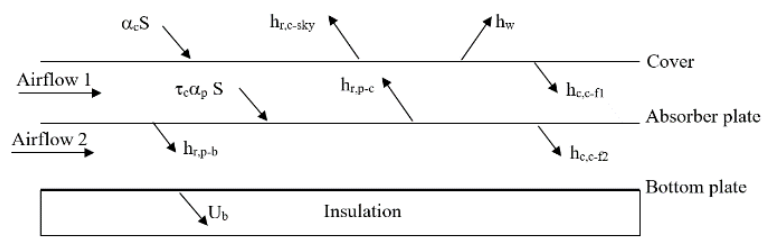

Fig 1: Heat transfer coefficients between DPSAH components

For cover:

$\alpha_{c} S+h_{r, p-c}\left(T_{p}-T_{c}\right)+h_{c, c-f 1}\left(T_{f 1}-T_{c}\right)=\left(h_{w}+\right.$

$\left.h_{r, c-s k y}\right)\left(T_{c}-T_{s k y}\right)$

For airflow between the cover and the absorber plate:

$h_{c, p-f 1}\left(T_{p}-T_{f 1}\right)=h_{c, c-f 1}\left(T_{f 1}-T_{c}\right)+\frac{2 \dot{m}_{1} c p_{a}\left(T_{f 1}-T_{a}\right)}{W L}$

(2)

For absorber plate:

$\alpha_{p} \tau_{c} S=h_{c, p-f 2}\left(T_{p}-T_{f 2}\right)+h_{r, p-c}\left(T_{p}-T_{c}\right)+$

$h_{r, p-b}\left(T_{p}-T_{b}\right)+h_{c, p-f 1}\left(T_{p}-T_{f 1}\right)$

For airflow between the absorber plate and the bottom plate:

$h_{c, p-f 2}\left(T_{p}-T_{f 2}\right)=h_{c, b-f 2}\left(T_{f 2}-T_{b}\right)+\frac{2 \dot{m}_{2} c p_{a}\left(T_{f 2}-T_{a}\right)}{W L}$

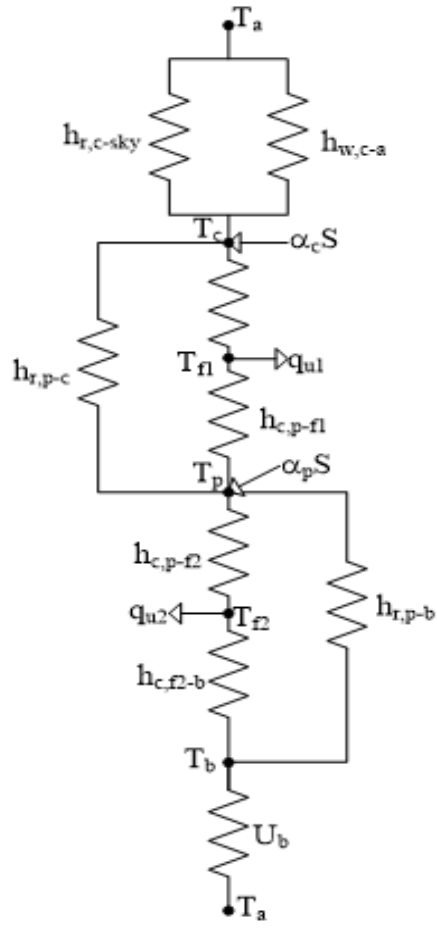

Fig 2: Thermal resistance network for parallel flow DPSAH

For the bottom plate:

$h_{c, b-f 2}\left(T_{f 2}-T_{b}\right)+h_{r, p-b}\left(T_{p}-T_{b}\right)=U_{b}\left(T_{b}-T_{a}\right)$

Some empirical relations were mentioned in the literature to estimate the heat transfer coefficients between the different surfaces in a SAH which are as follows [13]:

$h_{r, c-s k y}=\sigma \epsilon_{c}\left(T_{C}^{2}+T_{s k y}^{2}\right)\left(T_{c}+T_{s k y}\right)$

$h_{w}=5.7+3.8 V_{w}$

$h_{r, p-c}=\frac{\sigma\left(T_{p}^{2}+T_{c}^{2}\right)\left(T_{p}+T_{c}\right)}{\frac{1}{\epsilon_{p}}+\frac{1}{\epsilon_{c}}-1}$

$h_{r, p-b}=\frac{4 \sigma T_{p}^{3}}{\frac{2}{\epsilon_{p}}-1}$

$h_{c, f 1-c}=\frac{0.015 P_{\text {pas }} k_{a}}{4 A_{\text {pas }}} \operatorname{Pr}^{\frac{1}{3}}\left(\frac{4 \dot{m}_{\text {pas }}}{\mu_{a} P_{\text {pas }}}\right)^{0.8}$

$U_{b}=\left(\frac{t_{\text {ins }}}{k_{\text {ins }}}+\frac{t_{w}}{k_{w}}+\frac{1}{h_{w}}\right)^{-1}$

The sky temperature suggested by Swinbank [13] is:

$T_{\text {sky }}=0.0552 T_{a}^{1.5}$

Heat transfer coefficient between the upper airflow and the cover is [14]:

$h_{c, f 1-c}=0.664 * \operatorname{Pr}^{\frac{1}{3}}\left(\frac{\rho_{a} V_{i n} L}{\mu_{a}}\right)^{0.5} \frac{k_{a}}{L}$

The useful energy $\left(\mathrm{Q}_{\mathrm{u}}\right)$ of the air through the SAH can be estimated experimentally by

$Q_{u}=\dot{m} c_{p}\left(T_{o}-T_{i n}\right)$

Where $\dot{m}$ is the air mass flow across the SAH $(\mathrm{kg} / \mathrm{s}), \mathrm{c}_{\mathrm{p}}$ is the air specific heat $\left(\mathrm{J} / \mathrm{kg} .{ }^{\circ} \mathrm{C}\right), \mathrm{T}_{\mathrm{o}}$ and $\mathrm{T}_{\mathrm{in}}$ are the outlet and inlet air temperature $\left({ }^{\circ} \mathrm{C}\right)$, respectively. 
The instantaneous thermal efficiency ( $\square$ ) of the SAH is given by [9]

$\eta=\frac{Q_{u}}{S A}$

Equations 1 to 5 were solved by Engineering Equation Solver (EES) software for each hour to find the temperature of SAH components. The input data for solution are given in table 1, where the physical properties are built in the EES.

Table 1. Input parameters used for calculations

\begin{tabular}{|l|l|l|l|l|l|}
\hline $\begin{array}{l}\text { Paramet } \\
\text { er }\end{array}$ & Value & $\begin{array}{l}\text { Paramet } \\
\text { er }\end{array}$ & Value & $\begin{array}{l}\text { Paramet } \\
\text { er }\end{array}$ & $\begin{array}{l}\text { Valu } \\
\text { e }\end{array}$ \\
\hline $\begin{array}{l}\mathrm{A}_{\text {pas }}\left(\mathrm{m}^{2}\right) \\
2\end{array}$ & $\begin{array}{l}0.003 \\
\mathrm{~W}(\mathrm{~m})\end{array}$ & $\begin{array}{l}\mathrm{P}_{\text {pas }} \\
(\mathrm{m})\end{array}$ & $\begin{array}{l}0.273 \\
2\end{array}$ & $\mathrm{~L}(\mathrm{~m})$ & 1.2 \\
\hline $\begin{array}{l}\mathrm{V}_{\mathrm{w}} \\
(\mathrm{m} / \mathrm{s})\end{array}$ & 2.5 & $\varepsilon_{\mathrm{p}}$ & 0.95 & $\varepsilon_{\mathrm{c}}$ & 0.08 \\
\hline$\tau_{\mathrm{c}}$ & 0.88 & $\mathrm{t}_{\text {ins }}(\mathrm{m})$ & 0.05 & $\mathrm{\alpha}_{\mathrm{c}}$ & 0.08 \\
& & & & & \\
\hline
\end{tabular}

\section{EXPERIMENTAL SETUP AND PROCEDURE}

An outdoor SAHs was designed, constructed and implemented from available local materials in Baghdad, Iraq. Fig. 3. Shows the schematic diagram for the fabricated DPSAH with the measured temperature positions. A schematic cross section of V corrugated DPSAH is shown in Fig. 4. Air flows above and below the absorber plate at the same time and in the same direction. The collector consists of an ordinary glass cover of $4 \mathrm{~mm}$ thickness, the absorber plate was an Aluminum plate of $0.7 \mathrm{~mm}$ thickness, and foam of 50 $\mathrm{mm}$ thickness to insulate the sides and the base. A supporting frame to hold these components together was made from wood. It is measurements are $145 \mathrm{~cm}$ (length) $\times 97 \mathrm{~cm}$ (width) $\times 20 \mathrm{~cm}$ (height) for each. The absorber plate measurements are $120 \mathrm{~cm} \times 112 \mathrm{~cm}$. Corrugations were made with an angle of opening of $90 \mathrm{o}$ with equal sides of corrugation, the height of the corrugated is $55 \mathrm{~mm}$. The corrugated plate was fixed directly on a flat rear plate to form triangular passages. The absorber plate surface was coated with mat black paint to increase the absorbed heat. The tilt angle of the SAHs is 40o with horizontal to maximize the fall solar radiation on the absorber plate in winter. The latitude of Baghdad is equal to $33.3 \mathrm{oN}$. The solar air heaters were fixed to face south.

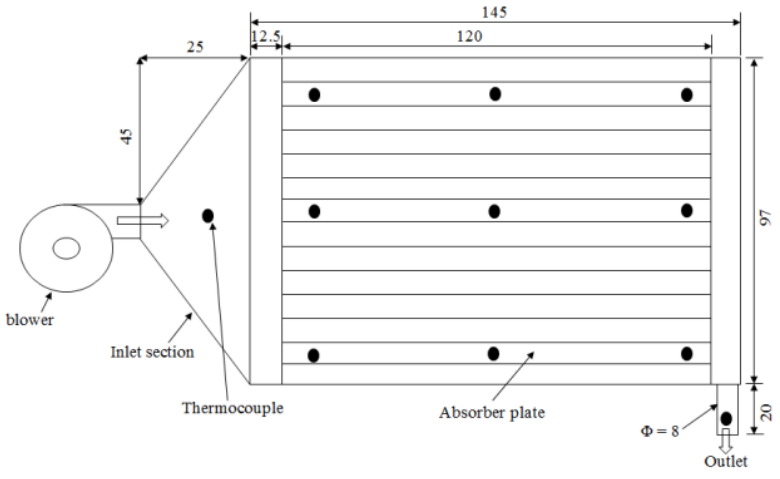

Fig. 3: A schematic diagram of the PSAH with the measured temperature positions. Dimensions in centimeters

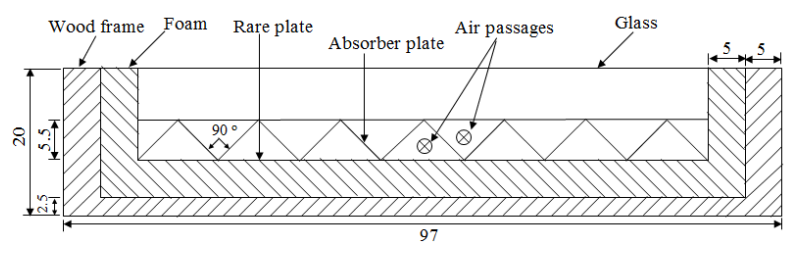

Fig. 4: A schematic of the DPSAH with V-corrugated absorber plate. Dimensions in centimeters

Hourly solar radiation data were taken from the Iraqi meteorological organization and seismology, while the ambient temperature was measured locally . Absorber plate, air inlet and outlet temperatures of SAH were recorded every 15 minute intervals using twelve thermocouples connected to a selector switch. Nine thermocouples were distributed on the absorber plate, three thermocouples were used to measure the inlet, lower and upper outlet air temperatures. Measurement of air flow rate was accomplished by means of a multi-function measurement instrument for air-conditioning, ventilation and indoor air quality manufactured by testo company, Lenzkrich, Germany, model 435

Experimental tests were implemented to calculate the thermal performance and the useful energy for DPSAH with Vcorrugated absorber plate. Experimental data were collected from 9 a.m. to 4 p.m. for each experiment for selected days in December 2016 and January 2017. The selected days have been choosen from clear sky days of these months. A constant air flow rate was used along the day for all tests. A mean value of the air flow rate has been calculated from five measurements across the solar air heater outlet. The density variation was treated according to the law of ideal gas to calculate the air mass flow rate through the SAH.

\section{RESULTS AND DISCUSSION}

The variation of ambient, mean absorber plate and outlet temperatures during the day is shown in Fig. 5. The variation in ambient temperature is a typical of local winter weather condition of Baghdad, Iraq. It is clearly observed that the mean absorber plate temperature is always greater than the outlet air temperature during the day. This is due to the heat transfer resistance between the corrugated channel walls and the flowing air stream. The difference between these two temperatures is usually small for liquid heating collectors, but may be significant for air heating collectors as obtained in this work. Also, there are a good agreement between theoretical and experimental results within an average difference of $3 \%$. The effect of airflow rate on the outlet air temperature is 
shown in Fig. 6. It is concluded that the outlet air temperature is proportional inversely with airflow rate.

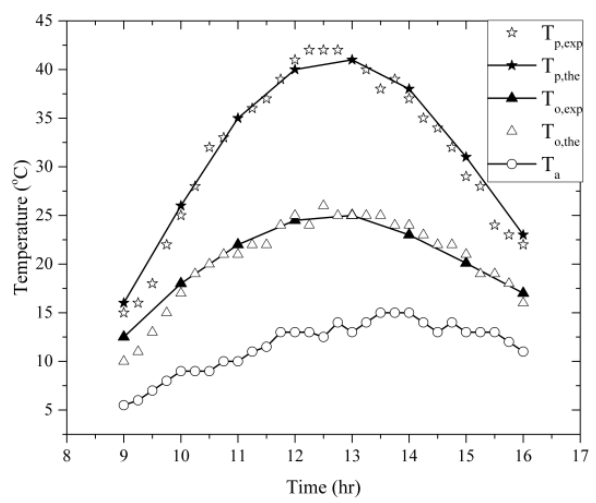

Fig. 5: Variation of ambient, absorber plate and outlet temperature with time of day.

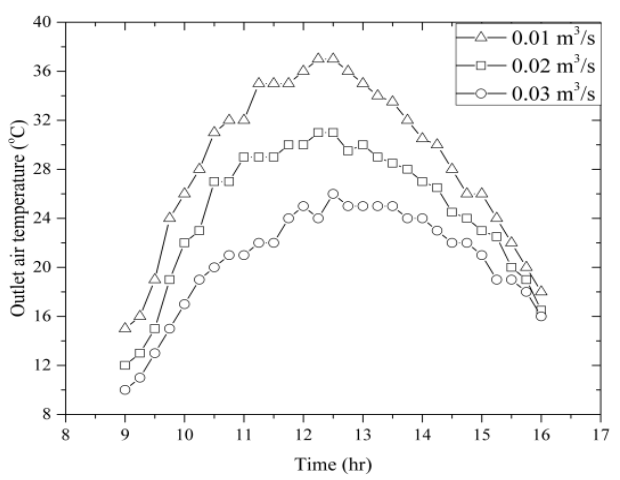

Fig. 6: Variation of outlet air temperature with time of day for different airflow rate.

Fig. 7 shows the variation of solar radiation and useful energy extracted from the DPSAH with day time. The amount of useful energy gained depends mainly on the thermal characteristics of the collector. Clearly, the useful energy is proportional to the quantity of airflow rate, i.e. when the airflow rate increased then the useful energy increases and vise verse. The theoretical and experimental results of the useful energy are coincided.

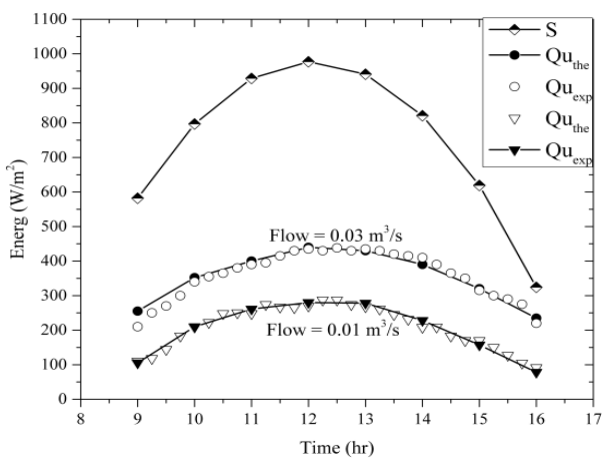

Fig. 7: Variation of solar radiation intensity and theoretical and experimental values of useful energy vs time of day.
The effect of airflow rate on the useful energy gained from an experimental study is shown in Fig. 8. It is clear that useful energy increases with increasing airflow rate. This is due to the fact that increasing the airflow rate leads to lower temperature levels of operation of the collector and hence less heat losses from the collector to the ambient. However, the absorber plate temperature is inversely variant with the airflow rate as shown in Fig. 9. The above results are in agreement with all the results cited in the literature. A maximum value of about $70{ }^{\circ} \mathrm{C}$ was obtained for the absorber plate temperature during midday at a airflow rate of $0.01 \mathrm{~m}^{3} / \mathrm{s}$.

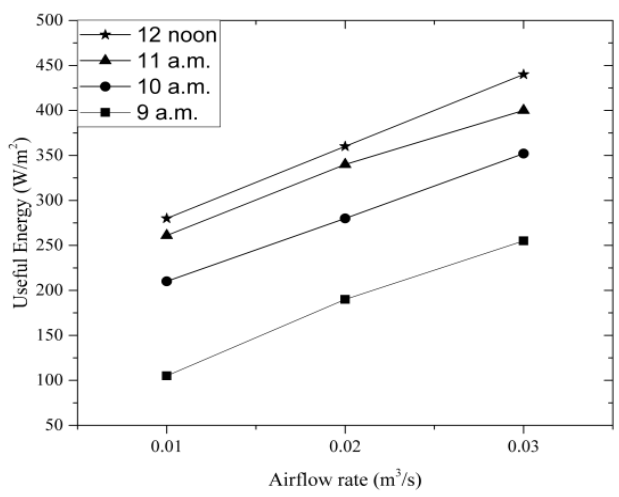

Fig. 8: Variation of useful energy with airflow rate for different times of day.

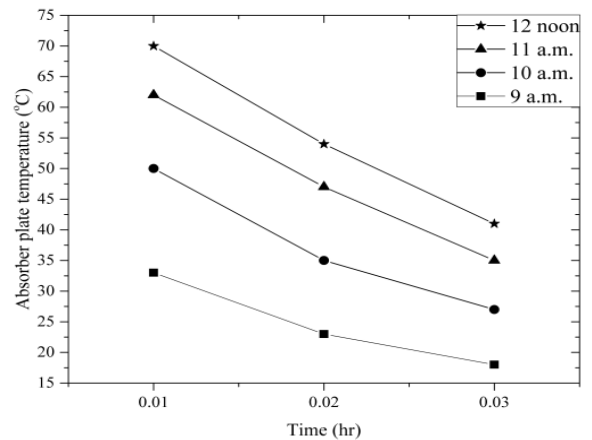

Fig. 9: Variation of the absorber plate temperature with airflow rate for different times of day

SAH can be extracted the heat from solar radiation intensity even in the cloudy sky as it recorded experimentally as shown in Fig. 10. It appears that the diffused radiation effect on the outlet air temperature was with an average value of $6{ }^{\circ} \mathrm{C}$ for the temperature difference across the SAH.

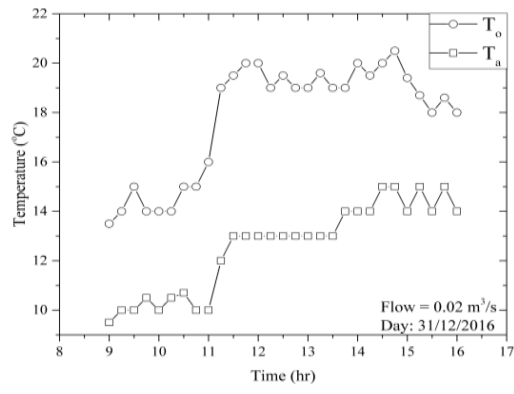

Fig. 10: Variation of ambient, absorber plate and outlet temperature with time of day. 
The characteristic efficiency curve of the present study is plotted in Fig. 11. Clear sky experimental data were used to plot this curve. The deviation of the experimental data on both sides is belongs to the variation of the weather condition during the test days. The value of intersection point of the average performance line with the $y$-axis is $63 \%$. The performance curve of the current DPSAH may be expressed as;

$\eta=0.63-17.4 \frac{T_{o}-T_{a}}{S}$

To verify the results, another SPSAH was built in the same specification of the DPSAH to hold a comparison between them. Fig. 12 shows the variation of the outlet air temperature across the two collectors. Clearly, the temperature across the DPSAH is greater than it across the SPSAH by $3{ }^{\circ} \mathrm{C}$ for the same airflow rate, this result is in enough agreement with published results of Hernandez and Quinonez [15].

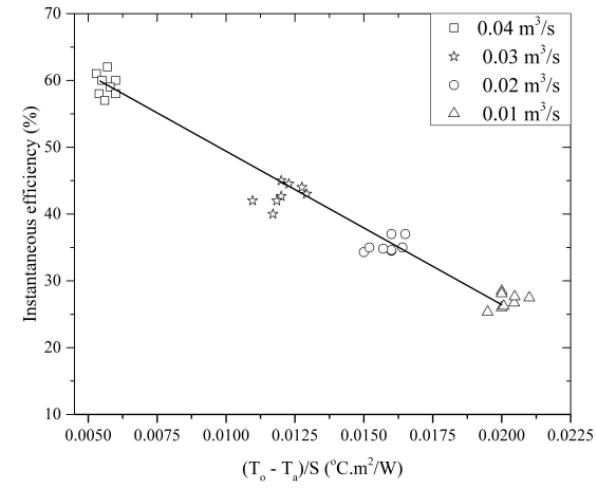

Fig. 11: Characteristic performance curve of the DPSAH

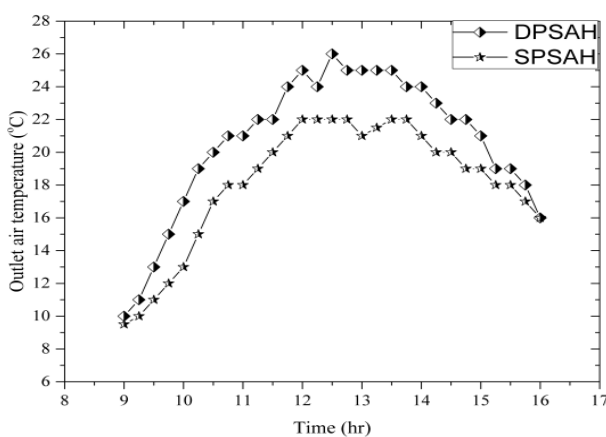

Fig. 12: Variation of outlet air temperature across DPSAH and SPSAH with time of day

\section{CONCLUSIONS}

From the obtained results for the experimental and theoretical study of the DPSAH, the following conclusions can be deduced:

1. The variation of the absorber plate, outlet air temperature, and useful energy gained during the study period was found to follow the solar radiation pattern.

2. Increasing the airflow rate through the collector increases the instantaneous collection efficiency and the useful energy gained, but reduces the absorber plate and outlet air temperatures correspondingly.
3. An air outlet temperature is about $37{ }^{\circ} \mathrm{C}$ for midday at airflow rate of $0.01 \mathrm{~m}^{3} / \mathrm{s}$ with a collection efficiency of $27 \%$.

4. The value of intersection point of the average performance line with the y-axis is $63 \%$.

5. Clearly, the temperature across the DPSAH is greater than its value across the SPSAH by $3{ }^{\circ} \mathrm{C}$ for the same airflow rate.

\section{NOMENCLATURE}

A cross section area $\left(\mathrm{m}^{2}\right)$

cp specific heat at constant pressure $(\mathrm{J} / \mathrm{kg} . \mathrm{K})$

$\mathrm{h}_{\mathrm{r}}$

$h_{c}$ radiation heat transfer coefficient $\left(\mathrm{W} / \mathrm{m}^{2} .{ }^{\circ} \mathrm{C}\right)$ convection heat transfer coefficient $\left(\mathrm{W} / \mathrm{m}^{2} .{ }^{\circ} \mathrm{C}\right)$ wind convection heat transfer coefficient $\left(\mathrm{W} / \mathrm{m}^{2} .{ }^{\circ} \mathrm{C}\right)$ thermal conductivity $(\mathrm{W} / \mathrm{m} . \mathrm{K})$ length of the solar collector $(\mathrm{m})$ mass flow rate $\left(\mathrm{kg} / \mathrm{m}^{3}\right)$ perimeter (m)

Prandtl number

$\mathrm{Q}_{\mathrm{u}} \quad$ useful energy (W)

solar radiation intensity $\left(\mathrm{W} / \mathrm{m}^{2}\right)$

insulation thickness (m)

wood thickness (m)

temperature $\left({ }^{\circ} \mathrm{C}\right)$

overall heat transfer coefficient $\left(\mathrm{W} / \mathrm{m}^{2} .{ }^{\circ} \mathrm{C}\right)$

wind velocity $(\mathrm{m} / \mathrm{s})$

inlet velocity $(\mathrm{m} / \mathrm{s})$

width of the collector (m)

glass cover absorptance

absorber plate absorptance

glass cover emittance

absorber plate emittance

glass cover transmittance

density $\left(\mathrm{kg} / \mathrm{m}^{3}\right)$

viscosity (Pa.s)

efficiency

Stefan-Boltzmann number

Subscripts:

$\begin{array}{ll}\text { a } & \text { air/ambient } \\ \text { b } & \text { bottom plate } \\ \text { c } & \text { cover } \\ \text { f1 } & \text { upper flow } \\ \text { f2 } & \text { lower flow } \\ \text { p } & \text { absorber plate } \\ \text { pas } & \text { passage }\end{array}$


sky

$$
\text { sky }
$$

\section{REFERENCES}

[1] R. Lahori, V. Gupta, and A. Yadav, "A Review on Different Methods Used for Performance Enhancement of Solar Air Heater," J. Energy Technol. Policy, vol. 6, no. 4, pp. 1-7, 2016.

[2] C. Ho, H. Chang, R. Wang, and C. Lin, "Analytical and experimental study of recycling baffled double-pass solar air heaters with attached fins," Energies, vol. 6, no. 4, pp. $1821-1842,2013$

[3] M. Y. Othman, B. Yatim, K. Sopian, and and M. N. A. Bakar, "Improving Air-Cooled Condenser Performance in Combined Cycle Power Plants Improving Air-Cooled Condenser Performance in Combined," J. ENERGY Eng., vol. December, pp. 121-126, 2006.

[4] H. Ali, A. Bhatti, and M. Ali, "An experimental investigation of performance of a double pass solar air heater with thermal storage medium," Therm. Sci., vol. 19, no. 5, pp. 1699-1708, 2015.

[5] M. Hedayatizadeh, F. Sarhaddi, A. Safavinejad, F. Ranjbar, and H. Chaji, "Exergy loss-based efficiency optimization of a double-pass/glazed v-corrugated plate solar air heater," Energy, vol. 94, no. January, pp. 799810, 2016.

[6] S. Dogra, N. Chauhan, and G. Bhardwaj, "Effect of artificial roughness on heat transfer and friction factor in a solar air heater," Int. J. Mech. Eng. Technol., vol. 4, no. 3, pp. 289-289, 2013.

[7] R. K. Ravi and R. P. Saini, "Experimental investigation on performance of a double pass artificial roughened solar air heater duct having roughness elements of the combination of discrete multi $\mathrm{V}$ shaped and staggered ribs," Energy, vol. 116, October, pp. 507-516, 2016.

[8] A. Sharma, G. Varun, and G. Bharadwaj, "Effect of Artificial Roughness on Heat Transfer and Friction Characterstics of Double Pass Solar Air Heater" Int. J. Mech. Ind. Eng., vol. 2, no. 3, pp. 56-60, 2012.

[9] S. González, S. Larsen, A. Hernández, and G. Lesino, "Thermal evaluation and modeling of a double-pass solar collector for air heating," Energy Procedia, vol. 57, pp. 2275-2284, 2014.

[10] A. A. Farhan, "Thermal Performance of Recycle Pass Solar Air Heater with V- Corrugated Absorber Plate," Int. J. Therm. Technol., vol. 6, no. 3, pp. 212-216, 2016.

[11] R. K. Ravi and R. P. Saini, "A review on different techniques used for performance enhancement of double pass solar air heaters," Renew. Sustain. Energy Rev., vol. 56, October, pp. 941-952, 2016.

[12] S. Chamoli, R. Chauhan, N. . Thakur, and J. Saini, "A review of the performance of double pass solar air heater," Renew. Sustain. Energy Rev., vol. 16, no. 1, pp. 481-492, 2012.

[13] J. A. Duffie and W. A. Beckman, Solar Engineering and Thermal Process, 3rd ed. New York: John Wiley and Sons, 2006.

[14] J. P. Holman, Heat Transfer, Tenth ed. McGraw-Hill, New York, 2010.

[15]A. L. Hernandez and J. E. Quinonez, "Analytical models of thermal performance of solar air heaters of doubleparallel flow and double-pass counter flow," Renew. Energy, vol. 55, pp. 380-391, 2013. 